\title{
Preface: Remote Sensing in Coastal Environments
}

\author{
Deepak R. Mishra ${ }^{1, *}$ and Richard W. Gould, Jr. ${ }^{2}$ \\ 1 Center for Geospatial Research, Department of Geography, University of Georgia, 210 Field Street, \\ Room 204, Athens, GA 30602, USA \\ 2 Bio-Optical/Physical Processes and Remote Sensing Section, Naval Research Laboratory Code 7331, \\ Building 1009, Stennis Space Center, MS 39529, USA; gould@nrlssc.navy.mil \\ * Correspondence: dmishra@uga.edu; Tel.: +1-706-542-8927
}

Academic Editor: Prasad S. Thenkabail

Received: 12 August 2016; Accepted: 15 August 2016; Published: 17 August 2016

\begin{abstract}
The Special Issue (SI) on "Remote Sensing in Coastal Environments" presents a wide range of articles focusing on a variety of remote sensing models and techniques to address coastal issues and processes ranging for wetlands and water quality to coral reefs and kelp habitats. The SI is comprised of twenty-one papers, covering a broad range of research topics that employ remote sensing imagery, models, and techniques to monitor water quality, vegetation, habitat suitability, and geomorphology in the coastal zone. This preface provides a brief summary of each article published in the SI.

Keywords: barrier island; sea turtle habitat; mangroves; Sahara Desert coast; kelp; spartina biomass; bathymetry; mangrove distribution; Brazilian Coast; hypoxia; Louisiana Shelf; UAV; harmful algal blooms; Yellow Sea; Po River delta; Venice Lagoon; suspended sediment dynamics; geostationary ocean color imager; mangrove leaf pigment; semi-analytical algorithm; seagrass biomass; shoreline change; northern Java Island; sun glint removal; bottom reflectance; coral reefs; coastal marsh; belowground biomass; root:shoot
\end{abstract}

\section{Overview and Scope}

Coastal ecosystems are regions of remarkable primary and secondary productivity, biodiversity, and high accessibility. Apart from supporting numerous physical and biological processes, they also act as recreational, leisure, and tourism centers. Encompassing a broad range of habitat types and harboring a wealth of species and genetic diversity, coastal ecosystems perform numerous vital ecosystem functions. In addition to serving as nursery grounds for many birds and aquatic organisms, coastal ecosystems play roles in regulating global hydrology and climate; the biological, physical, and chemical modifications of the water column, sediment, and submerged and emergent vegetation; the storage and cycling of nutrients; the filtration of pollutants from inland freshwater systems; and the protection of shorelines from erosion and storms. Consequently, there is a need for accurate, cost effective, frequent, and synoptic methods of characterizing and monitoring these complex ecosystems.

Remote sensing from in situ, airborne, and space-borne platforms can help satisfy the aforementioned criteria and can provide synoptic coverage over a range of spatial resolutions (coarse to fine), at regular temporal frequencies, to facilitate monitoring of coastal environments. This Special Issue on "Remote Sensing in Coastal Environments" is specifically aimed at addressing challenges related to assessing, quantifying, and monitoring near-shore shallow marine and open ocean processes, ecosystem productivity and biodiversity, interrelationships between vegetation and water quality, integrating remote sensing into coupled coastal biophysical forecast models, physical/biological interactions, hyperspectral applications, geomorphological changes, coastal hypoxia, and the use of LiDAR and unmanned aerial vehicles. The response to the Special Issue call was excellent, and following an extensive peer-review process, twenty-one papers were included 
in the issue. The section below briefly summarizes each paper published in the Special Issue on "Remote Sensing in Coastal Environments".

\section{Highlights of Research Articles}

In the study by El-habashi et al. [1], the authors described a neural network (NN) approach to detect and track Karenia brevis Harmful Algal Blooms (KB HABs) along the West Florida Shelf using VIIRS satellite observations. Because VIIRS does not have a $678 \mathrm{~nm}$ channel, which has been exploited in previous satellite approaches, the authors applied a NN approach to retrieve phytoplankton absorption at $443 \mathrm{~nm}$ (aph443) using remote sensing reflectance measurements from VIIRS channels at 486, 551 and $671 \mathrm{~nm}$. The aph443 values were correlated to chlorophyll-a concentrations and KB cell counts, and the VIIRS images were then used to delineate and quantify KB HABs. Comparisons with satellite retrievals obtained using other techniques and with in situ measurements reported over a four-year period, confirmed the effectiveness of the NN technique.

Long et al. [2] utilized an Unmanned Aerial Vehicle (UAV) equipped with a digital camera to produce Digital Surface Models (DSMs) and orthomosaics using a photogrammetry process. Three campaigns were conducted at a lagoon-inlet system within a three-month period. This low-cost, easy-to-use system yielded results of similar accuracy compared to traditional topographic survey methods. Changes identified between campaigns revealed erosion/accretion areas and the progradation of a sandspit. The approach offers new possibilities to validate detailed morphological predictions or to parameterize bottom friction in coastal numerical models.

Ko et al. [3] demonstrated the impact of including satellite imagery in simulations of coastal circulation and hypoxia. Using TRMM rainfall data to improve surface salinity flux estimates, and the diffuse attenuation coefficient $\left(\mathrm{K}_{\mathrm{d}}\right)$ from MODIS to improve estimates of solar penetration, they observed model improvements in water-column heat distribution and hypoxia extent, in comparison with in situ observations. Without inclusion of the satellite data, salinity and temperature errors led to model stratification that was too weak, and the model failed to capture observed spatial and temporal variability. Inclusion of the satellite data improved temperature and salinity predictions and strengthened vertical stratification, which improved prediction of bottom-water dissolved oxygen along the Louisiana coast.

Ximenes et al. [4] performed a spatial assessment of bioclimatic and environmental factors driving the distribution of mangrove species along the Brazilian coastline. They applied descriptive statistics and self-organizing maps, combining terrestrial and marine data to describe the impact of twenty-five environmental variables on species-level distributions. Results revealed three groups of correlated variables and unveiled new locations of extreme values of temperature and precipitation. This study provides insights about the distribution of mangrove species related to bioclimatic factors, and the proposed method may prove useful for policy makers and other stakeholders designing conservation strategies for coastal systems.

The analyses of Botha et al. [5] examined the effects of per-pixel variability in sunglint, atmospheric path length and directional effects on uncertainties in bathymetric retrievals from high-resolution satellite images. They performed a case-study to highlight retrieval errors from images acquired at non-optimal geometrical combinations, and they quantified the effects of variations in the environmental noise on water surface reflectance and the accuracy of environmental variable retrievals, using two WorldView-2 satellite images. This work illustrates that critical analysis of individual images, accounting for the entire sun elevation and azimuth and satellite sensor pointing and geometry, as well as anticipated wave height and direction, is required to ensure an image is suitable for aquatic data analysis.

O'Donnell and Schalles [6] assessed the linkages between abiotic drivers and marsh grass biomass response on the central Georgia coast of the United States. They used geospatial techniques to scale up in situ measurements of aboveground Spartina alterniflora biomass to landscape level estimates using 294 Landsat 5 TM scenes covering a twenty-eight year period. They examined three S. alterniflora 
size classes and observed that river discharge, total precipitation, minimum temperature, and mean sea level had positive relationships with and best explained biomass for all dates. They also noted aboveground biomass declines of 33\%, 35\%, and 39\% for S. alterniflora tall, medium, and short size classes, respectively, that correlated with drought frequency and severity trends.

Uhl et al. [7] developed a fully-automated feature detection processor to detect the presence of kelp in submerged habitats. Using hyperspectral aircraft remote sensing data, they spatially mapped kelp habitat in the subtidal zone of Germany. Their algorithm is designed to work without the need for field data or intense training, and consists of three steps: (1) an anomaly filter to remove effects of the water surface; (2) a derivative-based algorithm for kelp-feature extraction; and (3) an identification of kelp dominated pixels using specific spectral features. They compared the performance of their approach to a maximum likelihood classification method and diver transect maps, and observed higher accuracies with their new approach, to a depth of $6 \mathrm{~m}$, demonstrating the potential of this approach to map sublittoral kelp beds.

Using QuickBird and GeoEye satellite imagery, Otero et al. [8] assessed the use of automated remote sensing classification techniques (neural network, Maximum Likelihood) to calculate the extent and map the distribution of mangrove patches along the Sahara Desert Coast. The authors observed a better classification result using the Maximum Likelihood algorithm, with a detection accuracy of $87 \% \pm 2 \%$ for the northernmost contiguous mangrove patches of West Africa. The main source of error was the low spectral difference between mangroves and other types of terrestrial vegetation, which resulted in an erroneous classification between these two types of land cover. They also presented a detailed and reliable validation procedure for the land cover maps.

Dunkin et al. [9] used remote sensing data as input into a spatially-explicit, multi-criteria decision support model to determine nesting habitat suitability for Loggerhead Sea Turtles along the southeastern Florida Coast. Aircraft-collected high resolution topographic and bathymetric LiDAR data and concurrent hyperspectral imagery were used to explore habitat characteristics, by estimating morphological, environmental, and anthropogenic parameters that can impact turtle habitat suitability. Results indicate that the morphological parameters used as input into the model are well suited to provide a regional level approach, which can be implemented in various geographic locations to better communicate priorities and evaluate management strategies as a result of changes to the coastal environment.

Anderson et al. [10] used aerial imagery and LiDAR data to compare habitat type coverage with respective elevation, geomorphic features and short-term change between two barrier islands in the Northern Gulf of Mexico, one of which was naturally-formed and the other one was man-made. The authors used ground surveys, multi-year remotely-sensed data, habitat classifications and digital elevation models to quantify short-term habitat and geomorphic change, and to examine the relationships between habitat types and micro-elevation. Although vastly different in age, these two islands show remarkable commonalities among the traits investigated. Storm impacts had the most profound effects on vegetation and geomorphic features throughout the study period.

Ye et al. [11] characterized the bio-optical properties of the Yellow Sea by using in situ $\mathrm{R}_{\mathrm{rs}}$ data acquired in six cruises from 2003 to 2007 from 618 stations. The mixed classification method was able to separate the Yellow Sea in to four regions and five water types based on the spatial distribution of the water color from clear to very turbid consisting of classes A to E. They applied the classification scheme to MERIS data which showed that the water types have significant seasonal variations. Environmental forcing such as currents, tidal activity, fresh water discharges, monsoon winds, and typhoons could be linked to the spatio-temporal variability in water type in Yellow Sea.

Tosi et al. [12] developed a multi-band SAR methodology to integrate COSMO-SkyMed and ALOS-PALSAR images in order to measure displacement or land subsidence in coastal transitional environments such as Po River Delta and Venice coastland, northern Italy. They used 16 ALOS-PALSAR and 31 COSMO-SkyMed images spanning over four years and found a variable pattern of subsidence particularly in the inner basins of Venice and Po Delta lagoons. The multi-band combined approach 
developed in their study can be useful in monitoring ground elevation changes in lagoons, deltas, wetlands, and coastal farmlands.

Ody et al. [13] studied the potential of various satellite sensors including Landsat-8 OLI, MODIS Terra and Aqua, and SEVIRI MSG-3 to monitor and map suspended particulate matter (SPM) in the micro-tidal Rhône River plume. They developed regional algorithms using in situ SPM and satellite derived $R_{r s}$ data which were applied to the satellite datasets to monitor the spatio-temporal variations in SPM. Despite being a micro-tidal environment, they found a significant short-term (hourly) variations in SPM mainly controlled by wind and regional circulation. Ody et al. [13] also discuss the advantages and drawbacks of these satellite sensors in mapping SPM for the study site.

Cheng et al. [14] assessed diurnal and seasonal variations in the spatial distribution of total suspended particulate matter (TSM) using high frequency Geostationary Ocean Color Imager (GOCI) data. They found that the diurnal variations of TSM in the macro-tidal Yalu River estuary, China is strongly linked to the tidal cycle induced resuspension, producing two peaks corresponding to maximum flood and ebb events. The seasonal variability of TSM in the estuary being the highest level in winter and lowest in summer was also clearly identified. This study showed the potential of GOCI data in high frequency spatiotemporal monitoring of water quality.

Flores-de-Santiago et al. [15] analyzed the relationship between leaf reflectance and pigments, chlorophylls and carotenoid, in three mangrove species in order to assess their health condition. 360 leaves collected from a semi-arid forest of the Mexican Pacific showed the highest maximum correlations at green and red-edge bands for chl-a and chl-b. They found the vegetation index Red Edge Inflection Point Index (REIP) and Vogelmann Red Edge Index (Vog1) index as the optimal indices for chl-a and chl-b estimation in both stressed and healthy classes. They argued that using spectroscopy correlations at the leaf level is the first step towards accurate space-borne monitoring of large mangrove forests.

Han et al. [16] developed a generic semi-analytical algorithm to estimate suspended particulate matter from coastal waters using an extensive dataset acquired from coastal areas of Europe, French Guiana, North Canada, Vietnam, and China as part of the GlobCoast project. The SPM concentration range in the in situ data varied widely from 0.15 to $2626 \mathrm{~g} \cdot \mathrm{m}^{-3}$ to build robust algorithms. These algorithms were designed to work on various satellite sensors such as MERIS, MODIS, VIIRS, SeaWiFS, Landsat-8, and Sentinel 2 and 3. They demonstrated an improved performance by the generic semi-analytical algorithms which used a switching criteria based on the remote sensing reflectance value in red band (at $670 \mathrm{~nm}$ ).

Misbari and Hashim [17] used a two-step procedure to estimate seagrass total aboveground biomass (STAGB) using a 2009 Landsat TM and a 2013 Landsat OLI image in Straits of Johor, Malaysia. They demonstrated that Landsat data can be used to accurately estimate submerged STAGB for a multi-year change detection project. Their method revealed a decrease of $50.7 \mathrm{~kg}$ of STAGB from 2009 to 2013 which could be due to land reclamation in the intertidal mudflats to increase port facilities and coastal landscape development.

The study by Dewi et al. [18] combined crisp and unsupervised fuzzy c-means classification (FCM) methods to observe shoreline positions along a part of the northern coast of Java, Indonesia from 1994 to 2015. They reported a mix of gradual and abrupt changes in shoreline positions which could be associated with the inundations from 1994 to 2015 at the northern coastal area of Java, Indonesia. For example, the largest coastal inundations occurred between 1994 and 2000, when 739 ha changed from non-water and shoreline to water. Their method could serve as an effective way to map spatio-temporal variability in shoreline positions in other coastal areas.

Martin et al. [19] developed a WorldView-2 (WV-2) data based automatic deglinting procedure, which can be integrated in the radiative transfer modeling (RTM) inversion of the shallow water environments to simultaneously resolve water column IOPs, bathymetry and seafloor albedo contributions. The model was validated using in situ measurements and successfully applied to high resolution multispectral WV-2 satellite data with different levels of sun glint contamination. 
Their model could be an extremely useful tool to monitor water quality parameters, to estimate coastal bathymetry or to retrieve benthic maps.

Reichstetter et al. [20] analyzed the seperability of in situ hyperspectral bottom reflectance signatures for coral reef waters when observed at MODIS and SeaWiFS spectral resolution. They assessed 8280 scenarios by using different combinations of IOPs, depths, and bottom types and found that IOPs are not contaminated by bottom reflectance for brightest substrates at depths more than $17 \mathrm{~m}$ for MODIS and $19 \mathrm{~m}$ for SeaWiFS. They concluded that it is possible to differentiate between water column IOPs and bottom reflectance in shallow coral reef environments. Their model could offer improved accuracy for satellite based coral reef mapping studies.

O'Connell, Byrd, and Kelly [21] developed a Landsat 7 based hybrid model to estimate marsh belowground biomass and root:shoot ratio using \% foliar $\mathrm{N}$ and aboveground biomass as input. Wetland belowground biomass is linked to peat formation, which is a substantial carbon sink and helps stabilize the marsh ecosystem. They found significant relationships between remote sensing based estimates of aboveground plant characteristics, belowground biomass and root:shoot ratios. Landsat 7 based hybrid models explained up to $76 \%$ and $86 \%$ of variations in belowground biomass and root:shoot ratio, respectively. They concluded that spectral analysis is a promising tool for estimating relative measures of marsh biomass and biomass allocation.

Acknowledgments: We would like to express our gratitude to all authors who submitted their manuscripts to the Special Issue. Sincere thanks to the reviewers for providing constructive and prompt feedback necessary for a successful Special Issue. It was a rewarding experience working with the courteous editorial staff of the journal. Thank you for this opportunity to edit the Special Issue.

Conflicts of Interest: The author declares no conflict of interest.

\section{References}

1. El-habashi, A.; Ioannou, I.; Tomlinson, M.; Stumpf, R.; Ahmed, S. Satellite retrievals of Karenia brevis harmful algal blooms in the West Florida Shelf using neural networks and comparisons with other techniques. Remote Sens. 2016, 8. [CrossRef]

2. Long, N.; Millescamps, B.; Guillot, B.; Pouget, F.; Bertin, X. Monitoring the topography of a dynamic tidal inlet using UAV imagery. Remote Sens. 2016, 8. [CrossRef]

3. Ko, D.; Gould, R.; Penta, B.; Lehrter, J. Impact of satellite remote sensing data on simulations of coastal circulation and hypoxia on the Louisiana Continental Shelf. Remote Sens. 2016, 8. [CrossRef]

4. Ximenes, A.; Maeda, E.; Arcoverde, G.; Dahdouh-Guebas, F. Spatial assessment of the bioclimatic and environmental factors driving mangrove tree species' distribution along the Brazilian Coastline. Remote Sens. 2016, 8. [CrossRef]

5. Botha, E.; Brando, V.; Dekker, A. Effects of per-pixel variability on uncertainties in bathymetric retrievals from high-resolution satellite images. Remote Sens. 2016, 8. [CrossRef]

6. O'Donnell, J.; Schalles, J. Examination of abiotic drivers and their influence on spartina alterniflora biomass over a twenty-eight year period using Landsat 5 TM satellite imagery of the Central Georgia Coast. Remote Sens. 2016. [CrossRef]

7. Uhl, F.; Bartsch, I.; Oppelt, N. Submerged kelp detection with hyperspectral data. Remote Sens. 2016. [CrossRef]

8. Otero, V.; Quisthoudt, K.; Koedam, N.; Dahdouh-Guebas, F. Mangroves at their limits: Detection and area estimation of mangroves along the Sahara Desert Coast. Remote Sens. 2016, 8. [CrossRef]

9. Dunkin, L.; Reif, M.; Altman, S.; Swannack, T. A spatially explicit, multi-criteria decision support model for loggerhead sea turtle nesting habitat suitability: A remote sensing-based approach. Remote Sens. 2016. [CrossRef]

10. Anderson, C.; Carter, G.; Funderburk, W. The use of aerial RGB imagery and LIDAR in comparing ecological habitats and geomorphic features on a natural versus man-made barrier island. Remote Sens. 2016, 8. [CrossRef]

11. Ye, H.; Li, J.; Li, T.; Shen, Q.; Zhu, J.; Wang, X.; Zhang, F.; Zhang, J.; Zhang, B. Spectral classification of the Yellow Sea and implications for coastal ocean color remote sensing. Remote Sens. 2016. [CrossRef] 
12. Tosi, L.; Da Lio, C.; Strozzi, T.; Teatini, P. Combining L- and X-band SAR interferometry to assess ground displacements in heterogeneous coastal environments: The Po River Delta and Venice Lagoon, Italy. Remote Sens. 2016. [CrossRef]

13. Ody, A.; Doxaran, D.; Vanhellemont, Q.; Nechad, B.; Novoa, S.; Many, G.; Bourrin, F.; Verney, R.; Pairaud, I.; Gentili, B. Potential of high spatial and temporal ocean color satellite data to study the dynamics of suspended particles in a Micro-Tidal River Plume. Remote Sens. 2016, 8. [CrossRef]

14. Cheng, Z.; Wang, X.; Paull, D.; Gao, J. Application of the geostationary ocean color imager to mapping the diurnal and seasonal variability of surface suspended matter in a macro-tidal estuary. Remote Sens. 2016, 244. [CrossRef]

15. Flores-de-Santiago, F.; Kovacs, J.; Wang, J.; Flores-Verdugo, F.; Zhang, C.; González-Farías, F. Examining the influence of seasonality, condition, and species composition on mangrove leaf pigment contents and laboratory based spectroscopy data. Remote Sens. 2016. [CrossRef]

16. Han, B.; Loisel, H.; Vantrepotte, V.; Mériaux, X.; Bryère, P.; Ouillon, S.; Dessailly, D.; Xing, Q.; Zhu, J. Development of a semi-analytical algorithm for the retrieval of suspended particulate matter from remote sensing over clear to very turbid waters. Remote Sens. 2016. [CrossRef]

17. Misbari, S.; Hashim, M. Change detection of submerged seagrass biomass in shallow coastal water. Remote Sens. 2016. [CrossRef]

18. Dewi, R.; Bijker, W.; Stein, A.; Marfai, M. Fuzzy classification for shoreline change monitoring in a part of the Northern Coastal Area of Java, Indonesia. Remote Sens. 2016. [CrossRef]

19. Martin, J.; Eugenio, F.; Marcello, J.; Medina, A. Automatic sun glint removal of multispectral high-resolution Worldview-2 imagery for retrieving coastal shallow water parameters. Remote Sens. 2016. [CrossRef]

20. Reichstetter, M.; Fearns, P.; Weeks, S.; McKinna, L.; Roelfsema, C.; Furnas, M. Bottom reflectance in ocean color satellite remote sensing for coral reef environments. Remote Sens. 2015. [CrossRef]

21. O'Connell, J.; Byrd, K.; Kelly, M. A Hybrid model for mapping relative differences in belowground biomass and root: Shoot ratios using spectral reflectance, foliar $\mathrm{N}$ and plant biophysical data within coastal marsh. Remote Sens. 2015. [CrossRef]

(C) 2016 by the authors; licensee MDPI, Basel, Switzerland. This article is an open access article distributed under the terms and conditions of the Creative Commons Attribution (CC-BY) license (http://creativecommons.org/licenses/by/4.0/). 